"Gold price risk management through Nova 3 option strategy created by barrier options"

AUTHORS

ARTICLE INFO

DOI

RELEASED ON

JOURNAL

FOUNDER
Michal Šoltés iD https://orcid.org/0000-0002-1421-7177

Monika Harčariková

Michal Šoltés and Monika Harčariková (2016). Gold price risk management through Nova 3 option strategy created by barrier options. Investment Management and Financial Innovations, 13(1), 49--60. doi:10.21511/imfi.13(1).2016.04

http://dx.doi.org/10.21511/imfi.13(1).2016.04

Friday, 04 March 2016

"Investment Management and Financial Innovations"

LLC "Consulting Publishing Company "Business Perspectives"

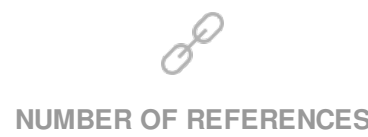

0
NUMBER OF FIGURES

0

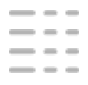

NUMBER OF TABLES

0

(C) The author(s) 2022. This publication is an open access article. 
Michal Šoltés (Slovakia), Monika Harčariková (Slovakia)

\title{
Gold price risk management through Nova 3 option strategy created by barrier options
}

\begin{abstract}
The paper is focused on selected aspects of the hedging using of Nova 3 option strategy created by barrier options, which are appropriate tools widely used for risk management of high risk underlying assets. Financial risk management using option strategies is an effective solution for limiting the loss from underlying asset's price development. The Nova 3 option strategy is suitable for hedging against increase in price of the underlying asset in case of its purchase in future. In our approach, European up and knock-in call options together with standard put and barrier put options are used for investigation of hedging strategies in increasing markets. Theoretical models of suitable hedged profit functions in analytical expressions are analyzed also from their benefits and risks point of view. Created combinations of these hedging variants have to meet the requirements of zero-cost option strategy. Based on the own theoretical results, the hedged profit portfolio is applied to SPDR Gold Shares, where due to the lack of data on real barrier option premiums, these were calculated according to Haug model. Designed secured variants through Nova 3 option strategy were analyzed and compared to each other with the recommendations of the best possibilities for investors.
\end{abstract}

Keywords: option strategy, hedging, barrier option, SPDR Gold Shares.

JEL Classification: G11, G13, G32.

\section{Introduction}

Over the past decades, globalization and capital liberalization have created a highly interconnected financial system, which is still exposed to increased volatility. Business leaders, firms and others have to face a big market risk, which is related with their business activities. The methods and mainly instruments used to manage the market risk are continuously developing. One of the favorite possibilities how to manage the risk is the hedging using financial derivatives. Financial derivatives, mainly options and option strategies, are used in risk management due to their liquidity, cost effectiveness and flexibility. Choosing of the effective hedging strategies is important for avoidance of disruptive consequences.

Today there are a lot of scientific studies focusing on implementing corporate risk management through hedging using derivatives. For example, papers (Bajo, Barbi and Romagnoli, 2014; Brown, 2001; Guay and Kothari, 2003) deal with the managing of risk using financial derivatives. Hankins (2011) investigates how the firms manage a risk by examining the interactions between financial and operational hedging and Loss (2012) studies optimal hedging strategies. Although over the years, numerous studies have investigated the hedging by using of option strategies, mainly classic vanilla options, there is limited research dealing with hedging using barrier options. We investigate this problem with the ambition to fill the gap. Therefore,

(C) Michal Šoltés, Monika Harčariková, 2016.

Michal Šltés, Associate Professor, Faculty of Economics, Technical University of Košice, Slovakia.

Monika Harčariková, Ph.D., Assistant Professor, Faculty of Economics, Technical University of Košice, Slovakia. the theoretical results of our analysis will be useful not only for financial institutions, but also for academic and research community.

Our approach is based on the barrier options as one part of option strategies, which is used for hedging. In general, options belong to the conditional contracts, where the buyers and the sellers do not have the equal rights and obligations. The buyer (the holder) of an option has the right to buy (a purchase call) or to sell (a purchase put) and the seller (the writer) has the obligation to sell (a sale call) or to buy (a sale put) an underlying asset at a prespecified time (also denoted as the maturity date or the expiration date) at a pre-specified price (also denoted as the strike price or the exercise price). The buyer pays an option premium (i.e. option price) to the seller for this right. The right can be exercised either at the maturity date (European style) or at any time within a pre-specified option expiration period (American style). Barrier options have special characteristics, which differentiate them from the standard vanilla options. The payoff of the barrier options depends on reaching or not reaching the specified barrier (placed UP or DOWN) of the underlying asset before expiration causing the possibility of option's activation/ deactivation (IN/OUT). There are 4 types of the barrier options, i.e. up and knock-in (UI), up and knock-out (UO), down and knock-in (DI), down and knock-out (DO), all for both call and put options. More detailed characteristics of barrier options are explained in Taleb (1997), Zhang (1998). Therefore, Nova 3 strategy can be created through 64 types of all barrier options' combinations. However, for hedging against a price increase, the best variants are those created using UI call options either with combination of the standard vanilla put options 
(suitable 9 ways of creation) or 4 types of barrier put options (suitable 16 ways of creation), which ensure the maximum buying price for hedgers subjects, as we will see later. Options strategies are presented in the studies (Hull, 2012; Kolb, 1995).

The main contribution of this study is to analyze the role of the hedging in reducing a particular risk. This is achieved by adding financial derivatives, usually options, to the risky asset (shares, commodities, currencies, interest rates and others) in order to create a hedged portfolio. The aim of the paper includes finding those hedged alternatives in analytical expression, which are suitable for hedging against a price increase in the market using Nova 3 option strategy created by barrier options. The aim of hedging is to minimize the risk of the loss, by its limitation to purchasing price. Our theoretical results of the hedged portfolios against a price increase are applied to SPDR Gold Shares, however they could be applied to any underlying assets. Selected hedging variants for these shares are designed and compared with each other and with the naked (unsecured) position. Based on our results, the recommendations for firms, which variant is the best in different underlying asset's price development, are given.

The structure of this paper is as follows. The next section introduces research methodology used in our approach. Section 2 proposes hedging variants for unsecured positions with using of option strategies. Section 3 proposes application of our research to SPDR Gold Shares and discusses the main results and conclusions are presented in final section.

\section{Research methodology}

The approach of the paper is based on option strategies, which represent the significant part of financial engineering. The methodology of the paper assumes an analytical expression of the vanilla and barrier options' profit functions. Using this analytical approach, we can explicitly design new hedging variants against a price increase. In this paper, the new option strategy, namely Nova 3, which was designed by Šoltés (2011), is used.

For using of the Nova 3 option strategy for hedging, understanding of its construction is needed. The Nova 3 option strategy is created by buying $n$ of put options with a strike price $X_{1}$, premium $p_{1 B}$ per option and at the same time by selling $n$ of put options with the higher strike price $X_{2}$, premium $p_{2 S}$ per option and by buying $n$ of call options with the highest strike price $X_{3}$, premium $c_{3 B}$ per option. European-style of options for the same underlying asset and with the same expiration time is used.

The papers (Rusnáková and Šoltés, 2012; Rusnáková, 2015; Šoltés and Rusnáková, 2012;
2013) deal with the hedging against a price increase or drop by means of different options strategies using vanilla and barrier options. Following the studies mentioned we analyze all possible ways of Nova 3 option strategy creation using barrier options with the aim to hedge against a price increase.

For our approach, all Nova 3 hedging variants against a price increase are investigated and only suitable hedging schemes involving the use of barrier options are analyzed in this paper. It has been found, that only combinations with up and knock-in call options fulfil our requirements for hedging. It is possible to design 9 types of hedging variants as combinations of up and knock-in call options together with vanilla put and barrier put options and 16 types as combinations of only barrier options, i.e. up and knock-in call options together with barrier put options. Our purpose is to find those possibilities against a price increase, which fulfil the conditions of zero-costs option strategies creation. Barrier levels are set for the lower levels $D<X$ and the upper levels $U>X$, where $X$ is the strike price. In general, there is valid that the lower barrier $D$ should be set under the actual spot price $S_{0}$ and the upper barrier $U$ should be set above the actual spot price $S_{0}$.

European vanilla and barrier options on SPDR Gold Shares are used with various strike prices and the barrier levels. The vanilla option prices are real data gained from www.finance.yahoo.com. Due to the fact, that data on barrier option prices are not publicly accessible, the values of the European barrier option prices are calculated. Black and Scholes (1973) introduced basic, generally used, option pricing model and their work is considered as significant added value in financial engineering theory and practice. However, this model is not designed for the pricing of the barrier options. Therefore, Merton (1973) modified classic version of this model for European down and knock-out call option. Later Rubinstein and Reiner (1991) applied the formulas for 8 types of the barrier options and Haug (2007) for all 16 types of European style of the barrier options. The barrier options can be priced by lattice techniques such as binomial (Cox, Ross and Rubinstein, 1979) and trinomial trees (Ritchen, 1995) or Monte Carlo simulation (Boyle, 1977). Mathematical structure of the barrier options was derived by Rich (1994). New pricing method of exotic options was discussed by Nishiba (2013).

1.1. Haug barrier option pricing model. Applying an approach of analytical model of Haug (2007), we compute theoretical price of standard European barrier call and put options, according to relations (1)-(18). 
Let us denote the call option $c$, the put option $p$, the actual underlying spot price $S_{0}$, the barrier level $B$, the strike price $X$, compensation $K$, the risk-free interest rate $r$ (derived from government bonds yields - U.S. Treasury rate, source: www.bloomberg.com), the implied volatility $\sigma$ (we use historical volatility),

$$
\begin{aligned}
& c_{D I(B>X)}=B-C+D+E \quad \eta=-1, \Phi=1, \\
& p_{D I(B \leq X)}=B-C+D+E \quad \eta=1, \Phi=-1, \\
& p_{D O(B \leq X)}=A-B+C-D+F \quad \eta=1, \Phi=-1, \\
& p_{U I(B>X)}=C+E \quad \eta=-1, \Phi=-1, \\
& p_{U O(B>X)}=A-C+F \quad \eta=-1, \Phi=-1,
\end{aligned}
$$

dividend yield $q$ and the time to maturity of the option $t$. Then the theoretical price of up and knockin call option (UI) for the barrier higher than the strike price and barrier put options (DI/DO the barrier lower than the strike price and UI/UI the barrier higher than the strike price) is calculated as:

where

$$
\begin{aligned}
& A=\Phi S_{0} e^{-q t} N\left(\Phi x_{1}\right)-\Phi X e^{-r t} N\left(\Phi x_{1}-\Phi \sigma \sqrt{t}\right), \\
& B=\Phi S_{0} e^{-q t} N\left(\Phi x_{2}\right)-\Phi X e^{-r t} N\left(\Phi x_{2}-\Phi \sigma \sqrt{t}\right), \\
& C=\Phi S_{0} e^{-q t}\left(B / S_{0}\right)^{2(\mu+1)} N\left(\eta y_{1}\right)-\Phi X e^{-r t}\left(B / S_{0}\right)^{2 \mu} N\left(\eta y_{1}-\eta \sigma \sqrt{t}\right), \\
& D=\Phi S_{0} e^{-q t}\left(B / S_{0}\right)^{2(\mu+1)} N\left(\eta y_{2}\right)-\Phi X e^{-r t}\left(B / S_{0}\right)^{2 \mu} N\left(\eta y_{2}-\eta \sigma \sqrt{t}\right), \\
& E=K e^{-r t}\left(N\left(\eta x_{2}-\eta \sigma \sqrt{t}\right)-\left(B / S_{0}\right)^{2 \mu} N\left(\eta y_{2}-\eta \sigma \sqrt{t}\right)\right), \\
& F=K\left(\left(B / S_{0}\right)^{\mu+\lambda} N(\eta z)+\left(B / S_{0}\right)^{\mu-\lambda} N(\eta z-2 \eta \lambda \sigma \sqrt{t})\right),
\end{aligned}
$$

and

$$
\begin{aligned}
& x_{1}=\frac{\ln \left(\frac{S_{0}}{X}\right)}{\sigma \sqrt{t}}+(1+\mu) \sigma \sqrt{t}, \\
& x_{2}=\frac{\ln \left(\frac{S_{0}}{B}\right)}{\sigma \sqrt{t}}+(1+\mu) \sigma \sqrt{t}, \\
& y_{1}=\frac{\ln \left(\frac{B^{2}}{S_{0} X}\right)}{\sigma \sqrt{t}}+(1+\mu) \sigma \sqrt{t}, \\
& y_{2}=\frac{\ln \left(\frac{B}{S_{0}}\right)}{\sigma \sqrt{t}}+(1+\mu) \sigma \sqrt{t}, \\
& z=\frac{\ln \left(\frac{B}{S_{0}}\right)}{\sigma \sqrt{t}+\lambda \sigma \sqrt{t},} \\
& \mu=\frac{r-q+\frac{\sigma^{2}}{2}}{\sigma^{2}}, \\
& \lambda=\sqrt{\mu^{2}+\frac{2 r}{\sigma^{2}}} .
\end{aligned}
$$


All relations of barrier options can be found in Iacus (2011). Our calculations of selected barrier options were processed in the statistical program $R$.

\section{Proposal of the hedging variants created by barrier options}

In this part, we have created theoretical models of hedging variants against price increase through which we hedge a spot position of the underlying asset using the Nova 3 option strategy created by barrier options.

Let us suppose that at time $T$ in the future we will buy $n$ pieces of the underlying asset, but we are afraid of its price increase. Profit function from the buying of the unsecured position at time $T$ is:

$$
P\left(S_{T}\right)=-n \cdot S_{T},
$$

where $S_{T}$ is the underlying spot price at time $T$. It is valid, that the higher the underlying spot price is, the higher costs, which we have to pay for purchase of the underlying asset, are.

Now, let us assume that we want to hedge the maximum buying price in the future $T$ using Nova 3 option strategy created by barrier options. Only up and knock in (UI) call options are suitable for hedging against the price increase. Other barrier call options (UO, DI, DO) secure the buying price only partially, therefore we do not consider these types of call options. There are 25 types of hedging variants in total, which can be created using UI call options together with the vanilla put or barrier put options. But in the next part we introduce only selected hedging variants, which fulfil the condition of the zero-cost option strategies, i.e. the selling option premium should be higher or equal than sum of buying option premium, as it is shown in the following relation:

$n \cdot p_{2 S} \geq n \cdot\left(p_{1 B}+c_{3 B U I}\right)$.

At first, let us construct Nova 3 option strategy by buying $n$ of put options with a strike price $X_{1}$, the premium $p_{1 B}$ per option and at the same time by selling $n$ of put options with the higher strike price $X_{2}$, premium $p_{2 S}$ per option and by buying $n$ of up and knock-in call options with the highest strike price $X_{3}$, premium $c_{3 B U I}$ per option and the barrier level $U$. The choice of the strike prices should be given as $X_{1}<X_{2}$ $<X_{3}$. We assume that the upper barrier $U$ is set above both the strike price $X_{3}$ and the actual spot price at time of issue $S_{0}$, i.e. $U>X_{3}$ and $U>S_{0}$. The profit functions from buying $n$ of put options:

$$
P_{1}\left(S_{T}\right)= \begin{cases}-n \cdot\left(S_{T}-X_{1}+p_{1 B}\right) & \text { if } S_{T}<X_{1}, \\ -n \cdot p_{1 B} & \text { if } S_{T} \geq X_{1},\end{cases}
$$

from selling $n$ of put options:

$$
P_{2}\left(S_{T}\right)= \begin{cases}n \cdot\left(S_{T}-X_{2}+p_{2 S}\right) & \text { if } S_{T}<X_{2}, \\ n \cdot p_{2 S} & \text { if } S_{T} \geq X_{2},\end{cases}
$$

and from buying $n$ of up and knock-in call options

$$
P_{3}\left(S_{T}\right)= \begin{cases}-n \cdot c_{3 B U I} & \text { if } S_{T}<X_{3}, \\ n \cdot\left(S_{T}-X_{3}-c_{3 B U I}\right) & \text { if } \max _{0 \leq t \leq T}\left(S_{t}\right) \geq U \wedge S_{T} \geq X_{3}, \\ -n \cdot c_{3 B U I} & \text { if } \max _{0 \leq t \leq T}\left(S_{t}\right)<U \wedge S_{T} \geq X_{3},\end{cases}
$$

are shown in an analytical expression due to easier way of understanding the hedging variant. In the context of previous conditions, the secured profit function (24) is created by adding the naked position (19) to the profit functions of individual options (21), (22) and (23).

$$
S P_{1}\left(S_{T}\right)=\left\{\begin{array}{l}
-n \cdot\left(S_{T}-X_{1}+X_{2}+p_{1 B}-p_{2 S}+c_{3 B U I}\right) \\
-n \cdot\left(X_{2}+p_{1 B}-p_{2 S}+c_{3 B U I}\right) \\
-n \cdot\left(S_{T}+p_{1 B}-p_{2 S}+c_{3 B U I}\right) \\
-n \cdot\left(S_{T}+p_{1 B}-p_{2 S}+c_{3 B U I}\right) \\
-n \cdot\left(X_{3}+p_{1 B}-p_{2 S}+c_{3 B U I}\right)
\end{array}\right.
$$

Generally, the higher the strike price is, the lower call option premiums and the higher put option premiums are and vice versa. Therefore, this hedging variant fulfils the condition of zero-cost option strategy (20). By comparison of the secured cost function (24) with the unsecured cost function (19) at the time $T$, we can conclude the following statements:

$$
\begin{aligned}
& \text { if } S_{T}<X_{1}, \\
& \text { if } X_{1} \leq S_{T}<X_{2}, \\
& \text { if } X_{2} \leq S_{T}<X_{3}, \\
& \text { if } \max _{0 \leq t \leq T}\left(S_{t}\right)<U \wedge S_{T} \geq X_{3}, \\
& \text { if } \max _{0 \leq t \leq T}\left(S_{t}\right) \geq U \wedge S_{T} \geq X_{3} .
\end{aligned}
$$

- For our hedging purpose, we assume $S_{T} \geq X_{3}$ at the expiration date and that the upper barrier $U$ will be reached during its time to maturity. With these two conditions fulfilled is the maximum constant buying price equal to $X_{3}+p_{1 B}-p_{1 S}+c_{3 B U I}$. By comparing with the unsecured function, the costs will be lower with hedging strategy if $S_{T} \geq X_{3}+p_{1 B}-p_{2 S}+c_{3 B U I}$. 
- If the underlying price is $S_{T} \geq X_{3}$, but the barrier is not reached during time to maturity, and $X_{2} \leq$ $S_{T}<X_{3}$, the costs of buying an underlying asset are equal to $S_{T}+p_{1 B}-p_{2 S}+c_{3 B U I}$, but these costs are lower in comparison with unsecured position due to hedging option strategy.

- If the underlying price is $X_{1} \leq S_{T}<X_{2}$, then the cost of the hedging strategy will be constant $X_{2}+p_{1 B}-p_{2 S}+c_{3 B U I}$, where lower costs of hedged position compared with the naked position are possible only for $S_{T}>X_{2}+p_{1 B}-p_{2 S}$ $+c_{3 B U I}$.

- In the case of the underlying price $S_{T}<X_{1}$, the profit function will be $S_{T}-X_{1}+X_{2}+p_{1 B}-p_{2 S}+c_{3 B U I}$, which means, that our costs for the last scenario would be higher than the unsecured position.

Proven by Taleb (1997), the vanilla option premiums are higher than the barrier option premiums, because the ability to exercise the barrier options is dependent on breaking the pre-set barrier. Therefore, the following hedging variant introduces the most interesting way of Nova 3 option strategy creation, which secures the lowest costs from the buying of the underlying asset.

$$
\begin{aligned}
& P_{1}\left(S_{T}\right)= \begin{cases}-n \cdot p_{1 B D I} & \text { if } \min _{0 \leq t \leq T}\left(S_{t}\right)>D \wedge S_{T}<X_{1}, \\
-n \cdot\left(S_{T}-X_{1}+p_{1 B D I}\right) & \text { if } \min _{0 \leq t \leq T}\left(S_{t}\right) \leq D \wedge S_{T}<X_{1}, \\
-n \cdot p_{1 B D I} & \text { if } S_{T} \geq X_{1},\end{cases} \\
& P_{1}\left(S_{T}\right)= \begin{cases}-n \cdot p_{1 B D O} & \text { if } \min _{0 \leq t \leq T}\left(S_{t}\right) \leq D \wedge S_{T}<X_{1}, \\
-n \cdot\left(S_{T}-X_{1}+p_{1 B D O}\right) & \text { if } \min _{0 \leq t \leq T}\left(S_{t}\right)>D \wedge S_{T}<X_{1}, \\
-n \cdot p_{1 B D O} & \text { if } S_{T} \geq X_{1},\end{cases} \\
& P_{1}\left(S_{T}\right)= \begin{cases}-n \cdot p_{1 B U I} & \text { if } \max _{0 \leq t \leq T}\left(S_{t}\right)<U \wedge S_{T}<X_{1}, \\
-n \cdot\left(S_{T}-X_{1}+p_{1 B U I}\right) & \text { if } \max _{0 \leq t \leq T}\left(S_{t}\right) \geq U \wedge S_{T}<X_{1}, \\
-n \cdot p_{1 B U I} & \text { if } S_{T} \geq X_{1},\end{cases} \\
& P_{1}\left(S_{T}\right)= \begin{cases}-n \cdot p_{1 B U O} & \text { if } \max _{0 \leq t \leq T}\left(S_{t}\right) \geq U \wedge S_{T}<X_{1}, \\
-n \cdot\left(S_{T}-X_{1}+p_{1 B U O}\right) & \text { if } \max _{0 \leq t \leq T}\left(S_{t}\right)<U \wedge S_{T}<X_{1}, \\
-n \cdot p_{1 B U O} & \text { if } S_{T} \geq X_{1},\end{cases}
\end{aligned}
$$

General description of the secured profit strategy (equation 29) created as a combination of the unsecured position (equation 19) together with the profit functions of the option positions (equation $25 / 26 / 27 / 28,22$ and 23 ) can be written as:

$$
S P_{2}\left(S_{T}\right)= \begin{cases}-n \cdot\left(S_{T}-X_{1}+X_{2}+p_{1 B b a r r i e r}-p_{2 S}+c_{3 B U I}\right) & \text { if } C_{1} \text { is fulfilled } \wedge S_{T}<X_{1}, \\ -n \cdot\left(X_{2}+p_{1 \text { Bbarrier }}-p_{2 S}+c_{3 B U I}\right) & \text { if } C_{2} \text { is fulfilled } \wedge S_{T}<X_{1}, \\ -n \cdot\left(X_{2}+p_{1 \text { Bbarrier }}-p_{2 S}+c_{3 B U I}\right) & \text { if } X_{1} \leq S_{T}<X_{2}, \\ -n \cdot\left(S_{T}+p_{1 \text { Bbarrier }}-p_{2 S}+c_{3 B U I}\right) & \text { if } X_{2} \leq S_{T}<X_{3}, \\ -n \cdot\left(S_{T}+p_{1 B b a r r i e r}-p_{2 S}+c_{3 B U I}\right) & \text { if } \max _{0 \leq t \leq T}\left(S_{t}\right)<U \wedge S_{T} \geq X_{3}, \\ -n \cdot\left(X_{3}+p_{1 B b a r r i e r}-p_{2 S}+c_{3 B U I}\right) & \text { if } \max _{0 \leq t \leq T}\left(S_{t}\right) \geq U \wedge S_{T} \geq X_{3} .\end{cases}
$$


Table 1 presents the summary of barrier conditions for particular put barrier options with premium $p_{1 B}$. By substituting corresponding barrier conditions in general profit function we get the profit function of the selected secured possibilities for the Nova 3 option strategy creation.

Table 1. Buying of put barrier options

\begin{tabular}{|l|c|c|c|}
\hline \multicolumn{1}{|c|}{ Type of put barrier option } & $C_{1}$ & $C_{2}$ & Conditions for barriers \\
\hline down and knock-in (DI) & $\min _{0 \leq t \leq T}\left(S_{t}\right) \leq D$ & $\min _{0 \leq t \leq T}\left(S_{t}\right)>D$ & $D<X_{1}$ \\
down and knock-out (DO) & $\min _{0 \leq t \leq T}\left(S_{t}\right)>D$ & $\min _{0 \leq t \leq T}\left(S_{t}\right) \leq D$ & $S_{0}$ \\
\hline up and knock-in (UI) & $\max _{0 \leq t \leq T}\left(S_{t}\right) \geq U$ & $\max _{0 \leq t \leq T}\left(S_{t}\right)<U$ & $U>X_{1}$ \\
\cline { 1 - 2 } up and knock-out (UO) & $\max _{0 \leq t \leq T}\left(S_{t}\right)<U$ & $\max _{0 \leq t \leq T}\left(S_{t}\right) \geq U$ & $U>S_{0}$ \\
\hline
\end{tabular}

According to amount of option premiums, it is possible to identify the better hedging cost variant in comparison of two possibilities in the relation:

$n \cdot\left(X_{3}+p_{1 B}-p_{2 S}+c_{3 B U I}\right)>n \cdot\left(X_{3}+p_{1 B \text { barrier }}-p_{2 S}+c_{3 B U I}\right)$.

From (30) we can conclude, that the first variant is better if:

$n \cdot\left(X_{3}-X_{3}+p_{1 B}-p_{1 B \text { barrier }}-p_{2 S}+p_{2 S}+c_{3 B U I}-c_{3 B U I}\right)>0$,

otherwise the second variant is better for case of relation (31) lower than zero.

Now, let us look at Nova 3 option strategy using only barrier options for its creation. An interesting possibility for hedging is by buying $n$ of up and knock-in put options with a strike price $X_{1}$, the premium $p_{1 B U I}$ per option, the barrier level $U$, which can be set as $U<X_{1} \wedge U=X_{1} \wedge U>X_{1}$, and at the same time by selling $n$ of down and knock-out put options with the higher strike price $X_{2}$, premium $p_{2 S D O}$ per option, the barrier level $D$ and at the same time by buying $n$ of up and knock-in call options with the highest strike price $X_{3}$, premium $c_{3 B U I}$ per option and the barrier level $U$. In this case, we assume the same upper barrier $U$ for UI put and UI call options.

The profit function of selling $n$ of down and knockout put options is:

$P_{2}\left(S_{T}\right)= \begin{cases}n \cdot p_{2 S D O} & \text { if } \max _{0 \leq t \leq T}\left(S_{t}\right) \leq D \wedge S_{T}<X_{2}, \\ n \cdot\left(S_{T}-X_{2}+p_{2 S D O}\right) & \text { if } \max _{0 \leq t \leq T}\left(S_{t}\right)>D \wedge S_{T}<X_{2}, \\ n \cdot p_{2 S D O} & \text { if } S_{T} \geq X_{2} .\end{cases}$

Then the secured strategy formed by individual functions (19), (27), (32) and (33) can be written as:

$$
S P_{3}\left(S_{T}\right)= \begin{cases}-n \cdot\left(S_{T}+p_{1 B U I}-p_{2 S D O}+c_{3 B U I}\right) & \text { if } \min _{0 \leq t \leq T}\left(S_{t}\right) \leq D \wedge \max _{0 \leq t \leq T}\left(S_{t}\right)<U \wedge S_{T}<X_{1}, \\ -n \cdot\left(2 S_{T}-X_{1}+p_{1 B U I}-p_{2 S D O}+c_{3 B U I}\right) & \text { if } \min _{0 \leq t \leq T}\left(S_{t}\right) \leq D \wedge \max _{0 \leq t \leq T}\left(S_{t}\right) \geq U \wedge S_{T}<X_{1}, \\ -n \cdot\left(X_{2}+p_{1 B U I}-p_{2 S D O}+c_{3 B U I}\right) & \text { if } \min _{0 \leq t \leq T}\left(S_{t}\right)>D \wedge \max _{0 \leq t \leq T}\left(S_{t}\right)<U \wedge S_{T}<X_{1}, \\ -n \cdot\left(S_{T}-X_{1}+X_{2}+p_{1 B U I}-p_{2 S D O}+c_{3 B U I}\right) & \text { if } \min _{0 \leq t \leq T}\left(S_{t}\right)>D \wedge \max _{0 \leq t \leq T}\left(S_{t}\right) \geq U \wedge S_{T}<X_{1}, \\ -n \cdot\left(S_{T}+p_{1 B U I}-p_{2 S D O}+c_{3 B U I}\right) & \text { if } \min _{0 \leq t \leq T}\left(S_{t}\right) \leq D \wedge X_{1} \leq S_{T}<X_{2}, \\ -n \cdot\left(X_{2}+p_{1 B U I}-p_{2 S D O}+c_{3 B U I}\right) & \text { if } \min _{0 \leq t \leq T}\left(S_{t}\right)>\mathrm{D} \wedge X_{1} \leq S_{T}<X_{2}, \\ -n \cdot\left(S_{T}+p_{1 B U I}-p_{2 S D O}+c_{3 B U I}\right) & \text { if } X_{2} \leq S_{T}<X_{3}, \\ -n \cdot\left(S_{T}+p_{1 B U I}-p_{2 S D O}+c_{3 B U I}\right) & \text { if } \max _{0 \leq t \leq T}\left(S_{t}\right)<U \wedge S_{T} \geq X_{3}, \\ -n \cdot\left(X_{3}+p_{1 B U I}-p_{2 S D O}+c_{3 B U I}\right) & \text { if } \max _{0 \leq t \leq T}\left(S_{t}\right) \geq U \wedge S_{T} \geq X_{3} .\end{cases}
$$

Another hedging variant which fulfil the zero-cost option strategy condition is created by buying $n$ of down and knock-out put options with a strike price $X_{1}$, the premium $p_{1 B D O}$ per option, the barrier level
$D$, and at the same time by selling $n$ of up and knock-out put options with the higher strike price $X_{2}$, premium $p_{2 S U O}$ per option, the barrier level $U$, which can be set as $U<X_{2} \wedge U=X_{2} \wedge U>X_{2}$, and 
at the same time by buying $n$ of up and knock-in call options with the highest strike price $X_{3}$, premium $c_{3 B U I}$ per option and the barrier level $U$. Again we assume the same upper barrier $U$ for UO put and UI call options. The profit function of selling $n$ of up and knock-out put options is:

$$
P_{2}\left(S_{T}\right)= \begin{cases}n \cdot p_{2 S U O} & \text { if } \max _{0 \leq t \leq T}\left(S_{t}\right) \geq U \wedge S_{T}<X_{2}, \\ n \cdot\left(S_{T}-X_{2}+p_{2 S U O}\right) & \text { if } \max _{0 \leq t \leq T}\left(S_{t}\right)<U \wedge S_{T}<X_{2}, \\ n \cdot p_{2 S U O} & \text { if } S_{T} \geq X_{2} .\end{cases}
$$

Combination of the unsecured position (19) together with individual option positions (26), (34) and (23) we design the next secured profit function strategy given as:

$$
S P_{4}\left(S_{T}\right)=\left\{\begin{array}{l}
-n \cdot\left(X_{2}+p_{1 B D O}-p_{2 S U O}+c_{3 B U I}\right) \\
-n \cdot\left(S_{T}+p_{1 B D O}-p_{2 S U O}+c_{3 B U I}\right) \\
-n \cdot\left(S_{T}-X_{1}+X_{2}+p_{1 B D O}-p_{2 S U O}+c_{3 B U I}\right) \\
-n \cdot\left(2 S_{T}-X_{1}+p_{1 B D O}-p_{2 S U O}+c_{3 B U I}\right) \\
-n \cdot\left(X_{2}+p_{1 B D O}-p_{2 S U O}+c_{3 B U I}\right) \\
-n \cdot\left(S_{T}+p_{1 B D O}-p_{2 S U O}+c_{3 B U I}\right) \\
-n \cdot\left(S_{T}+p_{1 B D O}-p_{2 S U O}+c_{3 B U I}\right) \\
-n \cdot\left(S_{T}+p_{1 B D O}-p_{2 S U O}+c_{3 B U I}\right) \\
-n \cdot\left(X_{3}+p_{1 B D O}-p_{2 S U O}+c_{3 B U I}\right)
\end{array}\right.
$$

Only in case of UI/UO put options, we can consider different levels of upper barriers $U_{1}$, i.e. $U_{1}<X_{1} \vee$ $U_{1}=X_{1} \vee U_{1}>X_{1}$ or $U_{1}<X_{2} \vee U_{1}=X_{2} \vee U_{1}>X_{2}$, but for UI call options $U_{2}$ should be only above $X_{3}$. The choice of the vanilla put or barrier put options for investors is connected with their expectations on underlying asset's price development, i.e. if there is expected rapid/slow drop or rapid/slow increase.

In this section some theoretical hedging variants using the Nova 3 option strategy created by barrier options for the risk management framework have been presented. Based on these theoretical statements, specific practical examples are discussed in the next section.

\section{Application to the SPDR Gold Shares}

In this section, we apply the proposed hedging variants to the gold market. Exchange traded funds (ETFs) belong to attractive possibilities of investing in gold market. We have chosen SPDR Gold Shares (GLD).

Let us suppose that in the future (20 January 2017) we are planning to buy SPDR Gold Shares in amount of 100 pieces, but we are afraid of its price increase. Therefore, we are planning to hedge against unfavorable price development. We are going to apply above mentioned Nova 3 option strategy formed by vanilla and barrier options on hedging to limit maximum buying price in future. Our proposed hedging variants have to fulfil the condition of the zero-cost option strategy at the time of issue according to relation (20).

$$
\begin{aligned}
& \text { if } \min _{0 \leq t \leq T}\left(S_{t}\right) \leq D \wedge \max _{0 \leq t \leq T}\left(S_{t}\right)<U \wedge S_{T}<X_{1}, \\
& \text { if } \min _{0 \leq t \leq T}\left(S_{t}\right) \leq D \wedge \max _{0 \leq t \leq T}\left(S_{t}\right) \geq U \wedge S_{T}<X_{1}, \\
& \text { if } \min _{0 \leq t \leq T}\left(S_{t}\right)>D \wedge \max _{0 \leq t \leq T}\left(S_{t}\right)<U \wedge S_{T}<X_{1}, \\
& \text { if } \min _{0 \leq t \leq T}\left(S_{t}\right)>D \wedge \max _{0 \leq t \leq T}\left(S_{t}\right) \geq U \wedge S_{T}<X_{1}, \\
& \text { if } \max _{0 \leq t \leq T}\left(S_{t}\right)<U \wedge X_{1} \leq S_{T}<X_{2}, \\
& \text { if } \max _{0 \leq t \leq T}\left(S_{t}\right) \geq U \wedge X_{1} \leq S_{T}<X_{2}, \\
& \text { if } X_{2} \leq S_{T}<X_{3}, \\
& \text { if } \max _{0 \leq t \leq T}\left(S_{t}\right)<U \wedge S_{T} \geq X_{3}, \\
& \text { if } \max _{0 \leq t \leq T}\left(S_{t}\right) \geq U \wedge S_{T} \geq X_{3} .
\end{aligned}
$$

3.1. Data description. On 21 July 2015 the SPDR Gold Shares were traded at 105.70 USD per share. There are chosen vanilla option prices from 21 July 2015 with the maturity date 20 January 2017 . There are European style of vanilla options on GLD considered. Barrier options are calculated in statistical program $\mathrm{R}$, where the input parameters used are the spot price of the underlying asset (115.70), time to maturity (550 days, i.e. from 21 July 2015 to 20 January 2017), interest rate $0.53 \%$ (gained from www.treasury.gov) and historical volatility $17.09 \%$. Due to simplifications, we assume transactions cost of 0 USD

The dataset for our analysis consists of 22 vanilla call/put options, 52 UI call options, 104 DI/DO put options and $130 \mathrm{UI} / \mathrm{UO}$ put options. Currency of an underlying asset and the option premiums is USD. We consider the strike prices of real vanilla options (gained from www.finance.yahoo.com) in the range of 85-122. The barriers were selected by authors, for lower barriers of DI/DO options in the range of 6090 and for upper barriers of UI/UO options in the range of 110-150, all in the multiplies of 10 .

On the basis of dataset, we analyze the hedging variants with the strike prices:
1. $X_{1}=90, X_{2}=116$ and $X_{3}=118$,
2. $X_{1}=90, X_{2}=110$ and $X_{3}=115$,
3. $X_{1}=100, X_{2}=110$ and $X_{3}=122$,

where in case of barrier options we consider lower barrier $D(70,80$ and 90$)$ and upper barrier $U(110$, 
120,130 and 140). There were totally 1170 hedging variants designed, but we present only selected variants, which meet the above stated requirements.

\subsection{Results.}

1. According to the first case, we will buy 100 put options with a strike price $X_{1}=90$, premium $p_{B}=3.73$ per option and at the same time, we will sell 100 put options with the strike price $X_{2}=116$, premium $c_{S}=$ 15.50 per option and at the same time we will buy 100 up and knock-in call options with the strike price $X_{3}=118$, the barrier level $U=130$, premium $p_{B U I}=4.53$. The hedged profit function from the purchase of 100 shares is given as:

$$
S P_{1}\left(S_{T}\right)= \begin{cases}-100 \cdot S_{T}-1,875.69 & \text { if } S_{T}<90, \\ -10,875.69 & \text { if } 90 \leq S_{T}<116, \\ -100 \cdot S_{T}+724.31 & \text { if } 116 \leq S_{T}<118, \\ -100 \cdot S_{T}+724.31 & \text { if } \max _{0 \leq t \leq T}\left(S_{t}\right)<130 \wedge S_{T} \geq 118, \\ -11,075.69 & \text { if } \max _{0 \leq t \leq T}\left(S_{t}\right) \geq 130 \wedge S_{T} \geq 118 .\end{cases}
$$

The construction of this hedging variant is the simplest of all. By comparing the functions (4.1) with the unsecured position (3.1) at various GLD price development during time to maturity and at maturity date, we can formulate following conclusions:

- If the spot price of shares during time to maturity grows above upper barrier $U=130$ and is higher than 118 USD at the future time $T$, then this hedging variant secures the maximum costs in amount of 11,075.69 USD.

- If the underlying spot price is higher than 108.76 USD, then our hedged variant is still better than the unsecured position, otherwise the unsecured position is better.

As it was mentioned earlier, hedging against a price increase secures a maximum acceptable underlying asset price. The actual spot price is 105.70 USD and we expect its price increase. In these cases the zerocost conditions (20) are preferred.
2. Next hedging variants are interesting from the point of view of their creation. There are two barrier options used. We will buy 100
A. DI put options,
B. DO put options,
C. UI put options,
D. UO put options,

with a strike price $X_{1}=90$, the barrier level $D=80$ (for DI and DO) or $U=130$ (for UI and UO), premium $p_{B D I}=2.18$ for DI $\left(p_{B D O}=0.25\right.$ for DO, $p_{B U I}=0.02$ for UI, $p_{B U O}=2.41$ for UO) per option and at the same time, we will sell 100 put options with the strike price $X_{2}=116$, premium $c_{S}=15.50$ per option and buy 100 up and knock-in call options with the strike price $X_{3}=118$, the barrier level $U=130$, premium $p_{B U I}=4.53$. The hedged profit functions from the buying of 100 shares for all 4 alternatives are shown in Table 2.

Table 2. Comparison of the profit functions for hedging variants $2 \mathrm{~A}-2 \mathrm{D}$

\begin{tabular}{|c|c|c|c|c|}
\hline $\begin{array}{l}\text { Scenarios of the spot price during time to } \\
\text { maturity } t \text { and at the maturity } T\end{array}$ & Hedging variant $2 \mathrm{~A}$ & Hedging variant $2 \mathrm{~B}$ & Hedging variant $2 \mathrm{C}$ & Hedging variant $2 \mathrm{D}$ \\
\hline $\min _{0 \leq t \leq T}\left(S_{t}\right) \leq 80 \wedge S_{T}<90$ & $-100 \cdot S_{T}-1,721.05$ & $-10,527.34$ & - & - \\
\hline $\min _{0 \leq t \leq T}\left(S_{t}\right)>80 \wedge S_{T}<90$ & $-10,721.05$ & $-100 \cdot S_{T}-1527.34$ & - & - \\
\hline $\max _{0 \leq \leq \leq T}\left(S_{t}\right)<130 \wedge S_{T}<90$ & - & - & $-10,504.51$ & $-100 \cdot S_{T}-1,743.88$ \\
\hline $\max _{0 \leq t \leq T}\left(S_{t}\right) \geq 130 \wedge S_{T}<90$ & - & - & $-100 \cdot S_{T}-1,504.51$ & -1074388 \\
\hline $90 \leq S_{T}<116$ & $-10,721.05$ & $-10,527.34$ & -105045 & $-10,74388$ \\
\hline $116 \leq S_{T}<118$ & $-100 \cdot S_{T}+87895$ & $-100 S_{T}+1,07266$ & $-100 S_{T}+1,09549$ & $-100 \cdot S_{T}+85612$ \\
\hline $\max _{0 \leq \leq \leq T}\left(S_{t}\right)<130 S_{T} \geq 11 \varepsilon$ & $-100 \cdot S_{T}+87895$ & $-100 \cdot S_{T}+1,072.66$ & $-100 \cdot S_{T}+1,095.49$ & $-100 \cdot S_{T}+85612$ \\
\hline $\max _{0 \leq t \leq T}\left(S_{t}\right) \geq 130 \wedge S_{T} \geq 118$ & $-10,921.05$ & $-10,727.34$ & -1070451 & -1094388 \\
\hline
\end{tabular}

The comparative analysis of the hedging variant $2 \mathrm{~A}-$ 2D from the Table 2 gives us the following results. The hedging variant $2 \mathrm{C}$ ensures us the lowest maximum costs at expected intervals of the spot price at the time $T$ in the amount of 107.04 USD per share. This hedging variant is created by the basic positions (put options and UI call options) and UI put options, where the higher volatility of the shares is expected. This possibility is the best for all analyzed hedging variants. Other designed hedging variants bring better results in comparison with the unsecured positions as well. 
For graphical comparison we choose only two of these proposed hedging variants $(2 \mathrm{~A}$ and $2 \mathrm{C}$ ) for all possible scenarios of the underlying asset's price development. Using the analytical expression of the profit functions (Table 2) and graphical expressions of $2 \mathrm{~A}$ and $2 \mathrm{C}$ secured possibilities (Figure 1), we can conclude, that:

- If the spot price of shares during time to maturity grows above the upper barrier $U=$ 130 and at the maturity date is higher than 105.05 for hedging variant $2 \mathrm{C}$ and 107.21 for hedging variant $2 \mathrm{~A}$, then the hedging variants

\section{Barrier D was reached and $U$ was not reached}

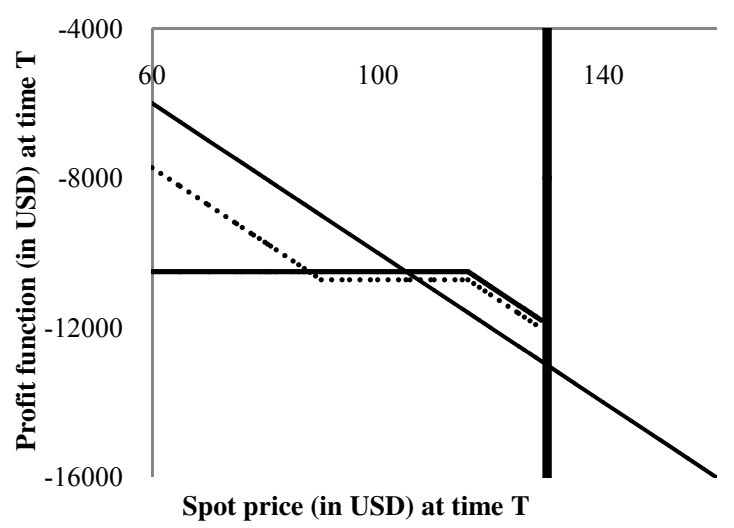

Barrier D and barrier U were not reached

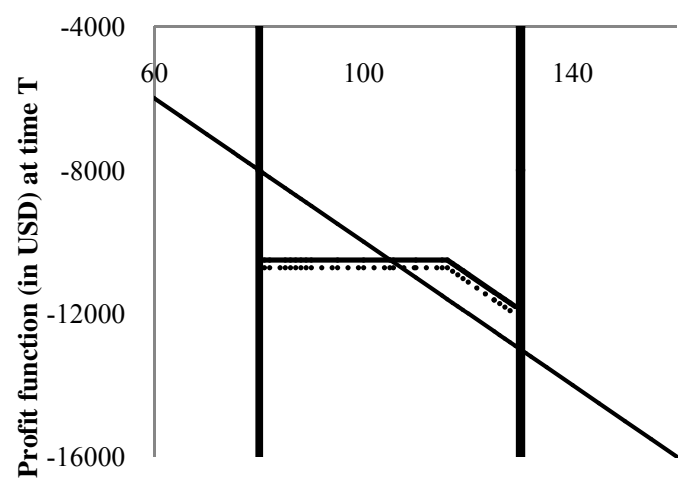

Spot price (in USD) at time $T$
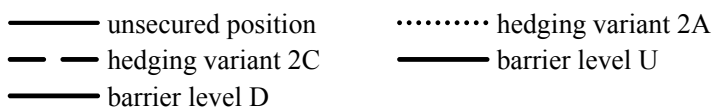

$2 \mathrm{~A}$ and $2 \mathrm{C}$ are still better than the unsecured position.

- If the upper $U=130$ and lower $D=80$ barrier levels were not reached during time to maturity, then there are the same conclusions as the previous one.

- But if only hedging variant $2 \mathrm{~A}$ and $2 \mathrm{C}$ are compared and the upper barrier $U=130$ was reached during time to maturity and the spot price of shares is higher than 88.06 , then the variant $2 \mathrm{C}$ is better, otherwise the variant $2 \mathrm{~A}$.

Barrier D was not reached and $U$ was reached

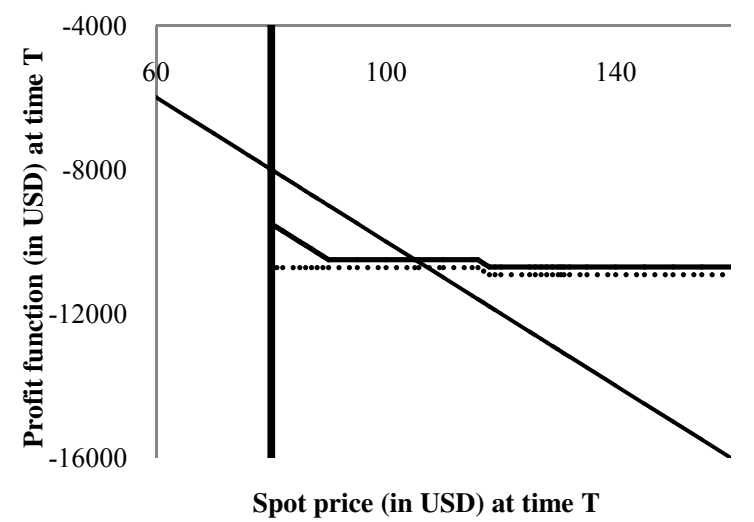

Barrier D and barrier $U$ were reached

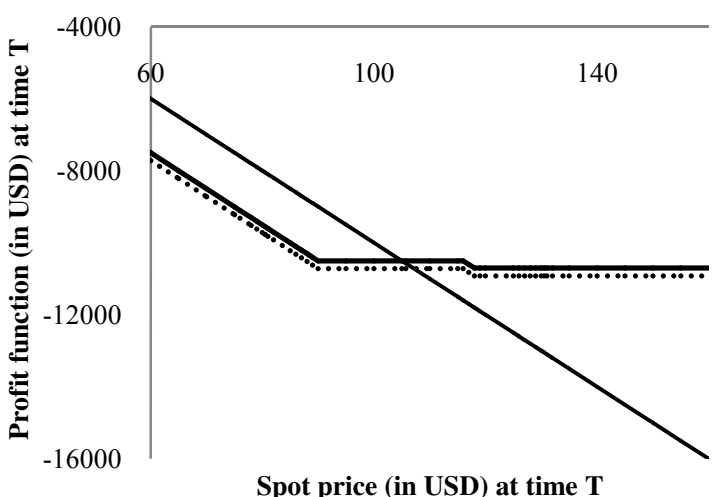

Spot price (in USD) at time T

Fig. 1. Comparison of the cost functions at time $T$ of the hedging variants $2 \mathrm{~A}$ and $2 \mathrm{C}$

3. In this case, we will buy of 100 UI put options with a strike price $X_{1}=90$, the barrier level $U=130$, premium $p_{B U I}=0.02$ per option and at the same time, we will sell 100 DO put options with the strike price $X_{2}=116$, the barrier level $D=80$ premium
$c_{S D O}=7.50$ per option and buy 100 up and knock-in call options with the strike price $X_{3}=118$, the barrier level $U=130$, premium $p_{B U I}=4.53$. The hedged profit function from the buying of 100 shares has the following form: 


$$
S P_{3}\left(S_{T}\right)= \begin{cases}-100 S_{T}+295.83 & \text { if } \min _{0 \leq t \leq T}\left(S_{t}\right) \leq 80 \wedge \max _{0 \leq t \leq T}\left(S_{t}\right)<130 \wedge S_{T}<90, \\ -200 S_{T}+9295.83 & \text { if } \min _{0 \leq t \leq T}\left(S_{t}\right) \leq 80 \wedge \max _{0 \leq t \leq T}\left(S_{t}\right) \geq 130 \wedge S_{T}<90, \\ -11304.17 & \text { if } \min _{0 \leq t \leq T}\left(S_{t}\right)>80 \wedge \max _{0 \leq t \leq T}\left(S_{t}\right)<130 \wedge S_{T}<90, \\ -100 S_{T}-2304.17 & \text { if } \min _{0 \leq t \leq T}\left(S_{t}\right)>80 \wedge \max _{0 \leq t \leq T}\left(S_{t}\right) \geq 130 \wedge S_{T}<90, \\ -100 S_{T}+295.83 & \text { if } \min _{0 \leq t \leq T}\left(S_{t}\right) \leq 80 \wedge 90 \leq S_{T}<116, \\ -11304.17 & \text { if } \min _{0 \leq t \leq T}\left(S_{t}\right)>80 \wedge 90 \leq S_{T}<116, \\ -100 S_{T}+295.83 & \text { if } 116 \leq S_{T}<118, \\ -100 S_{T}+295.83 & \text { if } \max _{0 \leq t \leq T}\left(S_{t}\right)<130 \wedge S_{T} \geq 118, \\ -11504.17 & \text { if } \max _{0 \leq t \leq T}\left(S_{t}\right) \geq 130 \wedge S_{T} \geq 118 .\end{cases}
$$

This strategy is less profitable than the others designed. In the case of unfavorable shares price development the maximum buying price of 115.04 USD per share is secured. If significant increase and simultaneously drop are expected, then the hedged variant is still better than the unsecured position. Only if the upper $U=130$ and the lower $D=80$ was reached during time to maturity and the spot price at the maturity date is above 113.04, the hedged variant 3 is better, otherwise the unsecured position.
4. In the last case let us form the Nova 3 strategy by buying of $100 \mathrm{DO}$ put options with a strike price $X_{1}$ $=90$, the barrier level $D=80$, premium $p_{B D O}=0.25$ per option and at the same time by selling $100 \mathrm{UO}$ put options with the strike price $X_{2}=116$, the barrier level $U=113$ premium $c_{S U O}=14.56$ per option and by buying 100 up and knock-in call options with the strike price $X_{3}=118$, the barrier level $U=130$, premium $p_{B U I}=4.53$. The hedged profit function from the buying of 100 shares is given as

$$
S C_{4}\left(S_{T}\right)= \begin{cases}-10,621.11 & \text { if } \min _{0 \leq t \leq T}\left(S_{t}\right) \leq 80 \wedge \max _{0 \leq t \leq T}\left(S_{t}\right)<130 \wedge S_{T}<90, \\ -100 S_{T}+978.89 & \text { if } \min _{0 \leq t \leq T}\left(S_{t}\right) \leq 80 \wedge \max _{0 \leq t \leq T}\left(S_{t}\right) \geq 130 \wedge S_{T}<90, \\ -100 S_{T}-1,621.11 & \text { if } \min _{0 \leq t \leq T}\left(S_{t}\right)>80 \wedge \max _{0 \leq t \leq T}\left(S_{t}\right)<130 \wedge S_{T}<90, \\ -200 S_{T}+9,978.89 & \text { if } \min _{0 \leq t \leq T}\left(S_{t}\right)>80 \wedge \min _{0 \leq t \leq T}\left(S_{t}\right) \geq 130 \wedge S_{T}<90, \\ -10,549.03 & \text { if } \min _{0 \leq t \leq T}\left(S_{t}\right)<130 \wedge 90 \leq S_{T}<116, \\ -100 S_{T}+978.89 & \text { if } \min _{0 \leq t \leq T}\left(S_{t}\right) \geq 130 \wedge 90 \leq S_{T}<116, \\ -100 S_{T}+978.89 & \text { if } 116 \leq S_{T}<118, \\ -100 S_{T}+978.89 & \text { if } \min _{0 \leq t \leq T}\left(S_{t}\right)<130 \wedge S_{T} \geq 118, \\ -10,821.11 & \text { if } \min _{0 \leq t \leq T}\left(S_{t}\right) \geq 130 \wedge S_{T} \geq 118 .\end{cases}
$$

This designed hedging variant 4 is more profitable than previous one, when the maximum buying price is ensured in amount of 108.21 USD per share for case of reaching the upper barrier 130 USD and the spot price of the shares on 20 January 2017 is higher than 118 USD. In order to compare designed hedging variants $(1,2 \mathrm{C}, 3$ and
4) with the unsecured position only for 2 scenarios of reaching the barrier level $U$, we illustrate these designs in Figure 2. We chose only scenarios for not reaching the lower barrier levels but reaching the upper barrier levels and the case for reaching both of barriers due to expectation of the price increase. 
Barrier D was not reached and barrier $\mathrm{U}$ was reached

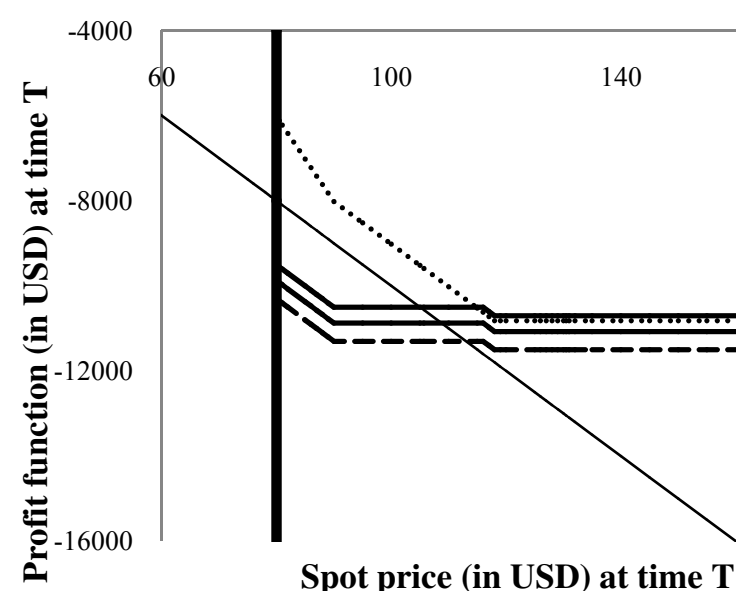

Spot price (in USD) at time $T$
Barrier D and barrier $\mathrm{U}$ were reached

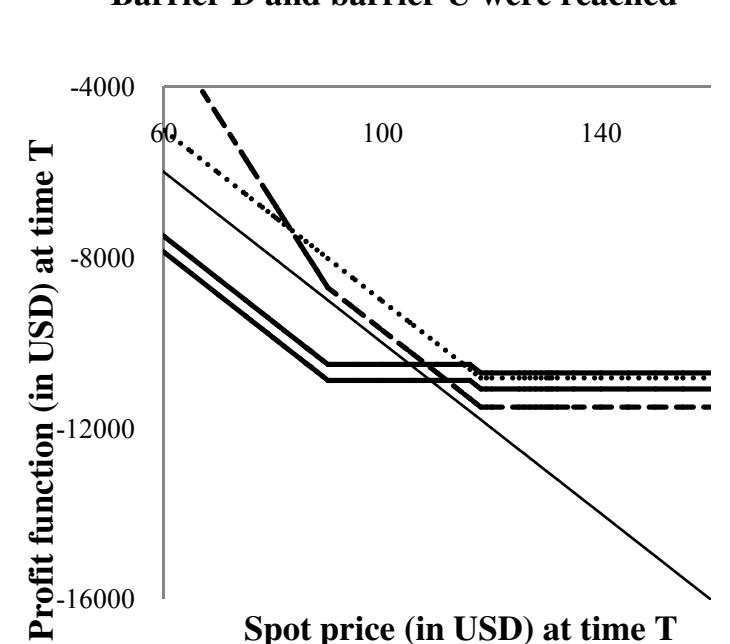

Spot price (in USD) at time T

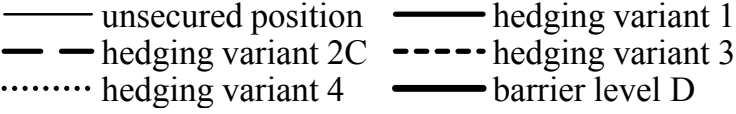

Fig. 2. Comparison of selected designed hedging variants if the upper and lower barrier was reached

According to Figure 2, we can conclude:

- If the lower barrier level $D$ was not reached and the upper barrier level $U$ was reached during time to maturity and the spot price of shares at the maturity date $T$ is above 114.83 , then the hedging variant $2 \mathrm{C}$ brings the lower cost for buying of shares, otherwise the hedging 4 is better.

- If both barrier levels were reached during time to maturity and the spot price of shares at the maturity date $T$ is in interval $<83.17,114.83\rangle$, then the hedging variant 4 is better. Otherwise, if the price is below 83.17 hedging variant 3 is better and if price is above 114.83 hedging variant $2 \mathrm{C}$ is better.

Choice of barrier option depends on hedger's expectations of underlying asset's price development. According to these expectations, knock-in barrier options are chosen in significantly price increase/drop (the option is activated after reaching the barrier) and knock-out options (the option is deactivated after reaching the barrier) in moderately price increase/drop. Therefore, all designed hedging variants provide an interesting opportunity for limiting maximum buying price of shares, but investors should note that if the price at the future time does not meet their expectations, they could gain loss in comparison to the unsecured position.

\section{Conclusion}

In recent years, firms still have to face many challenges. New opportunities are connected with rising of risks as well. This paper investigated the hedging against an increase using Nova 3 option strategy created by barrier options.
The paper provides the overview of the literature following with research methodology of the option pricing techniques. The profit functions of hedged strategies were derived for buying of an underlying asset in future. Investigations of hedging option strategies in the increasing markets are focused on the analysis of suitable hedging variants creation using barrier options. Analytical expressions of options were used in theoretical part of our approach for hedged portfolio creation. For our purpose there were appropriate only up and knock-in call options when the hedger wants to secure against increase. In fact, using of barrier options offers more hedging alternatives. There were 25 ways of Nova 3 option strategy creation analyzed in total (9 with both barrier and vanilla options and 16 with only barrier options used). Investigation of advantages and disadvantages of hedging strategies created allowed us to find suitable variants securing only the most likely unfavorable future price movement scenarios. The barrier options are cheaper than classic vanilla options and therefore, they are more suitable for hedging. However, due to data limitations of barrier options in the market, barrier option premiums were calculated according to Haug model.

The paper aimed to analyze and compare different Nova 3 option strategy creation using barrier options, which are relevant for gold market using the example SPDR Gold Shares. Numerical examples are illustrated through analytical expression of using of Nova 3 option strategy using barrier options with the aim of risk reduction. From the point of view of firms which want to hedge against unfavorable price development related to the protection of buying, we focus only for those combinations, which meet the 
requirements of zero-cost option strategy for creation representing the same amount of paid and received option premiums. Therefore, hedgers do not have to pay any option premium in the beginning. Followed the mentioned assumptions, the best variants of protection against a price increase of the shares were found. According to our analysis we recommend the hedging variant $2 \mathrm{C}$ as the best variant ensuring the lowest costs at expected intervals of the shares spot price at the maturity. Other designed variants are also interesting, therefore we should not exclude them. It is significant to select suitable combinations of the strike prices, the lower and upper barriers for achievement of the best hedging profit functions.

In this paper we demonstrate the significance of hedging for firms, which are planning to buy some underlying asset in future. Our approach can be applied to the various financial instruments. However, it is needed to realize the expectations of the gold price development as well as the willingness to undertake a risk, before the hedgers make a final decision about the choice of standard put/barrier put options.

Finally, in this paper, the focus was on firms as hedgers, but this approach could be useful for others as well, such as financial institutions which may create and offer investment products combined with upside protection in the market, academicians, etc. This approach can be helpful for various hedging option strategy creation in different financial markets.

\section{Acknowledgement}

The work was supported by the Ministry of Education of the Slovak Republic under grant VEGA No. 1/0986/15. Proposal of the dimensional models of the management effectiveness of ICT and information systems in health facilities in Slovakia and the economic-financial quantification of their effects on the health system in Slovakia.

\section{References}

1. Bajo, E., Barbi, M. and Romagnoli, S. (2014). Optimal corporate hedging using options with basis and production risk, North American Journal of Economics and Finance, 30, pp. 56-71.

2. Black, F. and Scholes, M. (1973). Pricing of Options and The Corporate Liabilities, Journal of Political Economy, 81 (3), pp. 637-654.

3. Boyle, P.P. (1977). Options: A Monte Carlo Approach, Journal of Financial Economics, 4, pp. 323-338.

4. Brown, G.W. (2001). Managing foreign exchange risk with derivatives, Journal of Financial Economics, 60, pp. 401-448.

5. Cox, J., Ross, S. and Rubinstein, M. (1979). Option Pricing, A Simplified Approach, Journal of Financial Economics, 7 (3), pp. 229-263.

6. Guay, W. and Kothari, S.P. (2003). How much do firms hedge with derivatives? Journal of Financial Economics, 70 (3), pp. 423-461.

7. Hankins, K.W. (2011). How Do Financial Firms Manage Risk? Unraveling the Interaction of Financial and Operational Hedging, Management Science, 57 (12), pp. 2197-2212.

8. Haug, E. (2007). The Complete Guide to Option Pricing Formulas, 2nd ed., Hardcover: McGraw-Hill, 232 p.

9. Hull, J.C. (2012). Options, Futures and Other Derivatives. New Jersey: Prentice-Hall, 888 p.

10. Iacus, S.M. (2011). Option pricing and estimation of financial models with $R$, 1st ed., Chichester: Wiley, 472 p.

11. Kolb, R.W. (1995). Understanding options, 1st ed., Hardcover: John Wiley \& Sons, Ltd., 400 p.

12. Loss, F. (2012). Optimal Hedging Strategies and Interactions between firms, Journal of economics \& management strategy, 21 (1), pp. 79-129.

13. Merton, R.C. (1973). Theory of rational option pricing, Journal of Economics and Management Science, 4 (1), pp. 141-183.

14. Nishiba, M. (2013). Pricing Exotic Options and American Options: A Multidimensional Asymptotic Expansion Approach, Asia-Pacific Financial Markets, 20 (2), pp. 147-182.

15. Rich, Don R. (1994). The mathematical foundations of barrier option pricing theory, Advances in futures and options research: a research annual, 7, pp. 267-312.

16. Ritchen, P. (1995). On Pricing Barrier Options, The Journal of Derivatives, 3 (2), pp. 19-28.

17. Rubinstein, M. and Reiner, E. (1991). Breaking Down the Barriers, Journal of Risk, 4 (8), pp. 28-35.

18. Rusnáková, M. and Šoltés, V. (2012). Long strangle strategy using barrier options and its application in hedging, Actual Problems of Economics, 134 (8), pp. 452-465.

19. Rusnáková, M. (2015). Commodity price risk management using option strategies, Agricultural EconomicsZemédělská ekonomika, 61 (4), pp. 149-157.

20. Šltés, M. (2011). Option strategies and their utilization in the financial markets, [Habilitation thesis]. Košice: Technical University of Košice, Faculty of Economics, 164 p.

21. Šoltés, V. and Rusnáková, M. (2012). Long Combo strategy using barrier options and its application in hedging against a price drop, Acta Montanistica Slovaca, 17 (1), pp. 17-32.

22. Šoltés, V. and Rusnáková, M. (2013). Hedging Against a Price Drop Using the Inverse Vertical Ratio Put Spread Strategy Formed by Barrier Options, Inzinerine Ekonomika - Engineering Economics, 24 (1), pp. 18-27.

23. Taleb, N.N. (1997). Dynamic Hedging: Managing Vanilla and Exotic Options. Hardcover: Wiley \& Sons, 528 p.

24. Zhang, P.G. (1998). Exotic options: A Guide to Second Generation Options, 2-nd ed., Singapore: World Scientific Publishing, 724 p. 